\title{
Impact of Big Five Personality Traits on Investment Decisions
}

\author{
${ }^{1}$ Vaishnavi Rathinasamy , ${ }^{2}$ Hemavathy Ramasubbian \\ ${ }^{1}$ MBA II year, ${ }^{2}$ Assistant Professor, Department of Business Administration, Avinashilingam \\ Institute for Home Science and Higher Education for Women, India.
}

\begin{abstract}
India has the mutual and growing workforce which helps in strong economic growth and initiative of government showcasing enormous opportunities for investments. Individual personality determines what type of investors they are and how they make their investments. This study aims to found an Impact of Big Five Personality Traits on Investment Decisions of an Investors in Coimbatore city. The variables which used in this study are Big Five Personality traits - Extroversion, Agreeableness, Conscientiousness, Neuroticism and Openness to Experience. Primary has been collected by using convenient sampling technique and well structured questionnaire where used to collect the data from respondents 152 samples are collected. Findings of this research study shows that Big Five Personality Traits influencing the Investment Decisions of the Investors.
\end{abstract}

Keywords: Extroversion, Agreeableness, Conscientiousness, Neuroticism, Openness, Investment Decisions.

\section{INTRODUCTION}

In current scenario, money plays a major role in everyone's life. For that investing or else saving the money are the most preferable way to overcome the future problems and needs. In this competitive era investors have various investment avenues to make their investments. Investment decisions are most important to make an investment. Everyone make an Investment decisions based on their personality traits (Dr.M.Babu, C.Dhanalakshmi, C.Hariharan 2018) and (Saloni Raheja, Dr.Babli Dhiman 2017).

Personality Traits which are influencing the behaviour of an individuals it reveals their characteristics like feelings and thoughts. In earlier theories Gordon's Allport's suggested 4000 personality traits, Rymond Cattell's 16 personality factors, Hans Eysenck's three - factory theory all this are too complicated and have a limited scope found by many researchers. As a result, the Five Factor theory was emerged to describe the essential traits by D.W.Fiske(1949) and late expanded it by Norman(1967), Smitch(1967), Goldberg(1981) and McCrae \& Costa(1987). Rather than the other Personality Traits mostly impacted Personality Traits on Investment Decisions are the Big Five Personality Traits.

\section{Objectives:}

To study the relationship between the personality of the individuals and their investment decisions. To analyse the Big Five Personality Traits such as Extroversion, Agreeableness, Conscientiousness, Neuroticism and Openness to Experience on investment behaviour to ascertain whether the above factors make an impact on Investment Decisions.

\section{Literature REVIEW}

\subsection{Personality Traits and Investment Decisions}

This study was conceptualized based on the popular Factor Analysis which widely used to analyse the Big Five Personality Traits of an investors, by the research study on Big Five Personality Traits two major traits which Extrovert and Openness are tested on stock market investment pattern using Factor Analysis proved as insignificant (Gowri Shankar.R., Dr.Tomy K. Kallarakal, 2018). It explores the two Personality Traits which Includes Conscientiousness and Openness to Experience, and Agreeableness were directly influence an Investment Performance. This study found out additionally that Conscientiousness and Openness to Experience and Extraversion were directly impacted the positive mood; then Agreeableness and Neuroticism were directly impacted a negative mood (Phung Thai Minh Trang, 2016). The study revealed that Personality Traits had some impact on Risk - Tolerance Behaviour of an Individuals Investment Decisions on stock, securities and bonds. The result of this research study imply when Financial Advisors giving Investment Advice to Private Investors should consider the Personality Traits and Risk Tolerance of an individual, among the other factors (Olga Pak, 2015). This research paper concluding that if Personality Traits and Behavioural Factors of an each Investors will known, it would be well equipped to guide the Investors by Financial Advisor to making the right Investment Decisions due to their behaviour and also helping to avoid the Financial Blunders in Investments (Renu Isidore, 2017). The researcher of this study find that Extraversion and Neuroticism influence Individuals' Behaviour 
significantly in the Financial Market. The suggestion of this study is get further benefits from analysing the individuals behaviour and personality traits before Invest in the Financial Markets (Andreas Oehler, Stefan Wendt, Florian Wedlich, Matthias Horn 2018). In this research study author concludes by using Chi - Square and Factor Analysis which demographic variables are not influence the Investment Decision of an Investors and Factor Analysis result shows that all Big Five Personality Traits are influence the Investment Decision of an Investors in the stock market (Dr. M. Babu, C. Dhanalakshmi, C. Hariharan, 2018). This research paper found a positive relationship and also Financial Efficacy between Neuroticism, Conscientiousness and Long - term Investment Decisions are supported the mediating effect of it which resulted by bootstrapping (Baqir Husnain, Syed Zulfiqar Ali Shah, Tasneem Fatima, 2019). This research paper showed that Neurotic individuals tend to had negative attitude towards investments in stock market. Then perceived the Behavioural Control of an individuals influenced by the Big Five Personality Traits on stock investments. Also experienced significantly affect the relationship between stock investment intention and attitude, as well as linkages between Extroversion and subjective norm, attitude and perceived behavioural control (Cheng-Po Lai 2019). The study found out the positive influence of Extraversion, Agreeableness, Conscientiousness and Openness to Experience and also found that negative influence of Neuroticism on individual innovativeness and satisfaction with life perceptions (Imran Ali, 2017). This research paper found the relationship between Personality Traits and Behavioural Bias are statistically significant when Investors take Investment Decisions. Investors preferred to invest in particular Investment Options due to their need and their mind-set (Saloni Raheja, Dr. Babli Dhiman 2017). The research study found the Personality Traits do not have much influence towards the attitude of an Investor, they most wisely invest in diversified portfolio to minimize their risk (P.Parameswari, Dr. Jayasree Krishnan, 2015). From the research study found that Agreeableness, Neuroticism and Openness were correlated strongly to Risk Tolerance, but Extraversion and Conscientiousness were not correlated with Risk Tolerance (Garima Mathur, Navita Nathani, 2019). The result of the study showed a Positive relationship between Openness to Experience, Extraversion and Short Term Investment Decisions and also Neuroticism, Conscientiousness and Long Term Investment Decisions existed Positive relationship. The results are confirmed the moderating effect of need for cognition are Extrovert and Neurotic investors on Financial - Self Efficacy (Baqir Husnain, 2019). The researcher exhibits the findings which had a strong relationship between Big Five Personality Traits on Self Perceived Investment Knowledge and Investors Attitude Characteristics (M. A. Vijaya, Dr. A. Somu,
2016). From this research study concludes that investors were during their trading activities PMEX are alleged with psychological biases and personality traits. (Zafar uz Zaman Anjum, Nazar H.Phulpoto, Sohail A.Memon, Raza M.Pahore, M.Imran, Zuhaibuddin Bhutto, 2019). The study concludes that Financial Literacy did not have significant effect on Investment Decisions through Big Five Personality Traits (Nasrullah Hamza, Gulzar-eHijri, Imtiaz Arif, 2019). The result of the study explores there is a significant relationship between that Personality Traits (Extroversion, Agreeableness, Neuroticism, Openness to Experience and Financial Literacy) on Risk tolerance of the young Potential Investors. There is a insignificant relationship to the risk tolerance based on the independent variables of gender and investment experience. The final result concludes that there is a significant relationship between Investment Decision and the young potential investor's risk tolerance (Ang Shiao Zhuan,Chuah Chea Ying, Kui Siew Boon, Soo Li Hui,Wong Chin Hong, 2016). This study explored their result which Investment Decision was influenced by attitude, PBC and intention and also find out of the four main construct subjective norms factor value doesn't load effectively on the behaviour (Hemavathy Ramasubbian, Kirupa Priyadarsini, M Vasuki, 2018). The researcher found the outcome of the study exhibit which that independent variables (market factors, overconfidence factor, prospect factors, anchoring factors and Behavioural Factors) are important for dependent variable (Investment Decision Making)(Penerbit Akademia Baru, 2017).

\section{METHODOLOGY}

This study done in Coimbatore city because it is a tier three city with large number of population where the people are migrated from some other places to Coimbatore for education purpose and also for employment. Hence there is a lot of opportunities for investments among the Coimbatore people. This study done through descriptive research and used convenient sampling technique to collect the data. For this study used Primary data it was collected from the respondents by using structured questionnaire (which used it as a survey instrument in this study) which adapted from the article of Naela Jamal Rushdi and Dr. Bimal Jaiswal (2014) and modified it to do this study. In the structured questionnaire used Five point scale and Multiple Choice Questions. In Coimbatore city there are totally 12 number of blocks, in that 3 blocks (Karamadai, Sulur, Periyanaikkanpalayam) were selected through lottery method from 3 blocks 165 samples were collected out of that 13 samples are invalid Approximately 45 to 55 samples are collected from each block. The collected data were organised and arranged in a systematic manner and uploaded in SPSS software then analysed the data through it and interpreted based on their output from the analysis. Major tool used for this analysis is Factor 
Analysis using 25 statements of Big Five Personality Traits under each traits carried 5 variables

\section{ANALYSIS AND INTERPRETATION}

Factor analysis aims to reduce too many variables into a few factors. In this study personality traits have too many variables (25 variables) for that using Factor analysis and reduce it into a five major factors under each factors carries five variables

Table 4.1 (a) Reliability Statistics

\begin{tabular}{|r|r|r|}
\hline $\begin{array}{c}\text { Cronbach's } \\
\text { Alpha }\end{array}$ & $\begin{array}{c}\text { Cronbach's Alpha - } \\
\text { Standardized Items }\end{array}$ & Number of Items \\
\hline .916 & .898 & 69 \\
\hline
\end{tabular}

The five major factors were again subjected to the Confirmatory Factor analysis to analyse whether these variables are statistically significant on Investors Personality Traits when making their investment decisions.

Table 4.1(b) KMO and Bartlett's Test

\begin{tabular}{|c|c|c|}
\hline Kaiser-Meyer-Olkin & $\begin{array}{l}\text { Measure of Sampling } \\
\text { Adequacy. }\end{array}$ & $\mathbf{. 8 7 2}$ \\
\hline $\begin{array}{c}\text { Bartlett's Test of } \\
\text { Sphericity }\end{array}$ & Approx. Chi-Square & $1.851 \mathrm{E} 3$ \\
\hline & Df & 300 \\
\hline & Sig. & .000 \\
\hline
\end{tabular}

KMO (Kaiser- Meyer-Olkin) test was conducted to measure the Sample Adequacy and it was found as 0.872 it shows in the Table 4.1(b). According to Kaiser (1974), the acceptance level minimum is 0.5 if the value lies between 0.5 to 0.6 are mediocre values or else if the value is more than 0.7 considered as good, $<0.8$ means great and 0.9 were excellent. In the above table, the KMO value is 0.872 hence it is considered as great and acceptable one.

Bartlett ${ }^{e e}$ s Test of Sphericity is $1.851 \mathrm{E} 3$ which significant at .000 thus showing the correlations among variables in the data were neither singular nor identity correlation matrix. Thus, having examined preliminary test namely Kaiser-Meyer-Olkin Measure of Sampling Adequacy (KMO) and Cronbach Alpha, the results in all cases justify that the use of factor analysis is an appropriate tool for the data obtained through the construct of 5 points Likert scale. Since the average of the communality value is greater than 0.6 and the sample size exceeded 152 respondents (Kaisere's criterion of retaining the number of factors), the researcher retained the default number of factors as generated by SPSS taking into account (that is, eigenvalues greater than 1). Confirmatory Factor analysis was conducted to measure the variable consistency to the construct. Using the CFA five factors were loaded. Five factors with eigenvalues greater than one were produced and percent of the total explained the variance. In this analysis, 25 statement has been taken to find the effect of variables. It was found that 7 of the variables KMO value is in the acceptable at minimum level $0.5,8$ of the variables with the value of 0.6 at the medium level, 9 variables were consistently higher than 0.7 at the good level and finally, 1 of the variables were at greater level with 0.8 value. The number of variables loaded in each factor is given below in Table - 4.1(c).

Table 4.1 (c) Rotated Component Matrix

\begin{tabular}{|c|c|c|c|c|c|}
\hline & & & mpon & & \\
\hline & 1 & 2 & 3 & 4 & 5 \\
\hline EXTN 1 & .588 & & & & \\
\hline EXTN 2 & & & & .689 & \\
\hline EXTN 3 & & & & .697 & \\
\hline EXTN 4 & & & & .576 & \\
\hline EXTN 5 & & & & .535 & \\
\hline AGBS 1 & & & & & .748 \\
\hline AGBS 2 & & & & & .557 \\
\hline AGBS 3 & .722 & & & & \\
\hline AGBS 4 & .758 & & & & \\
\hline AGBS 5 & .654 & & & & \\
\hline COTS 1 & .726 & & & & \\
\hline COTS 2 & .614 & & & & \\
\hline COTS 3 & .602 & & & & \\
\hline COTS 4 & & .506 & & & \\
\hline COTS 5 & .538 & & & & \\
\hline NETM 1 & & .654 & & & \\
\hline NETM 2 & & .643 & & & \\
\hline NETM 3 & & .832 & & & \\
\hline NETM 4 & & .742 & & & \\
\hline NETM 5 & & .710 & & & \\
\hline OPTE 1 & & & 601 & & \\
\hline OPTE 2 & & & .737 & & \\
\hline OPTE 3 & & & .755 & & \\
\hline OPTE 4 & & & .517 & & \\
\hline OPTE 5 & & & .702 & & \\
\hline
\end{tabular}

Factor I - Under factor one eight variables are loaded with value ranging from 0.538 to 0.758 . That Eight variables are mentioned here: I am friendly and sociable, some people think of me generous and kind, I generally try to be thoughtful and careful, I am willing to listen others advice, I keep my belongings tidy and clean, I am pretty good about myself so as to get things done on time, I manage my time well before setting down to work and I think I am able to get organised.

Factor II - Six variables are identified under factor 2 with value ranging from 0.506 to 0.832 . the six variables are specified here: I think that I am dependable or reliable, I often feel no as good as others, I often get angry when I get stress, I often feel nervous and sensitive on emotion, 
sometimes I feel completely worthless and I am easy to giving up when the things go wrong.

Factor III - In factor 3 five variables are loaded with value ranging from 0.517 to 0.755 . That five variables are I am curious by the patterns about art and nature, I often try new ideas in each investment, I am often enjoy playing with theories and abstract ideas, I love to learn new knowledge and I am creative and enjoy in different field

Factor IV - Four variables are loaded under factor 4 with value ranging from 0.535 to 0.697 . I often feel as bursting with energy, I am a joyful and brave, I am very positive person and I love make new friends and able maintain good relationship with them are the four variables loaded under the factor four.

Factor $\mathbf{V}$ - Two items are loading with value ranging from 0.557 to 0.748 . I seldom get into arguments with my family and co - workers and some people think I'm not selfish and cheerful are the two variables which loaded under factor five.

\section{RESULTS AND DISCUSSION}

Big Five Personality Traits are analysed by using Factor Analysis. The result of the Factor Analysis shows all the 25 items are classified under 5 Factors. Due to that all the Big Five Personality Traits are impact the Investment Decisions of an Investors. Based on the results It was concluded with suggestions to all the promoters, mutual funds, real estate brokers, share market holders and speculators should study and analyse the Investors Personality Traits before make an Investments. It makes a major role of impact on an investors investment decisions.

\section{Conclusion}

This research study takes a significant value for every investment sector which includes investors by their own, investment advisors and investment marketers. The findings of this research study can used to guide the clients who make an investment in mutual fund or in investment markets to make an analysis of their personality traits before making their investments and also used for academician studies and researchers to get some ideas related to their research which about Impact of Big Five Personality Traits on Investment Decisions.

\section{REFERENCES}

[1] Andreas Oehler, Stefan Wendt, Florian Wedlich \& Matthias Horn (2018), Investors' Personality Influences Investment Decisions: Experimental Evidence On Extraversion And Neuroticism, Journal Of Behavioral Finance, 19:1, 2018, Pp:3048 .

[2] Anuradha Samal, A. K.Das Mohapatra (2017), Factors Influencing Investment Decisions In Indian Capital Market: A Study On Retail Investors In The Odisha Province, International Journal Of Management And Applied Science, Issn: 2394-7926 Volume-3, Issue-8, 2017, Http://Iraj.In
[3] Baqir Husnain Syed Zulfiqar Ali Shah And Tasneem Fatima (2019), Effect Of Neuroticism, Conscientiousness On Investment Decisions. Mediation Analysis Of Financial Self-Efficacy, City University Research Journal, Volume 09 Number 01 January 2019 Pp 15-26.

[4] Barrick, M.R., Mount, M.K. (1991). The Big Five Personality Dimensions and Job Performance: a Meta-Analysis. Personnel Psychology, vol-44, pp:1-26.

[5] Dr. M. Babu, C. Dhanalakshmi, C. Hariharan (2018), Impact Of Personality Traits On Investment Decision In Stock Market, Excel International Journal Of Multidisciplinary Management Studies(Eijmms), ISSN 2249- 8834, Vol.8 (3), March (2018), Pp. 43-53

[6] Garima Mathur, Navita Nathani (2019), Personality Traits And Risk Tolerance Among Young Investors, International Journal Of Innovative Technology And Exploring Engineering (IJITEE) ISSN: 2278-3075, Volume-8 Issue-10, 2019, Pp: 2019 -2023 .

[7] Gowri Shankar.R., Dr.Tomy K. Kallarakal (2018), A Study on the Impact of Big Five Personality Traits and Demographics on the it Working Professionals Stock Investment Decision, International Journal of Innovations \& Advancement in Computer Science(IJIACS), 2018, Vol 7, issue 3, ISSN 2347 8616, pp 111- 120

[8] Hemavathy Ramasubbian, 2Kirupa Priyadarsini 3M Vasuki (2018), Investment Decisions In Real Estate: A Theory Of Planned Behavior (TPB) Based Approach, International Journal Of Pure And Applied Mathematics, Volume 119 No. 17 2018, Pp:2377-2381, ISSN: 1314-3395 (On-Line Version), Url: Http://Www.Acadpubl.Eu/Hub/

[9] Jhansi Rani Boda, Dr. G. Sunitha (2018), Investor's Psychology In Investment Decision Making: A Behavioral Finance Approach, International Journal Of Pure And Applied Mathematics, Volume 119 No. 7 2018, ISSN: 1311-8080 (Printed Version); ISSN: 1314-3395 (On-Line Version), Pp:1253-1261, Url: Http://Www.Ijpam.Eu

[10] M. A. Vijaya, Dr. A. Somu (2016), The Relationship Between Big Five Personality Factors, Self Perceived Investment Knowledge And Investor Attitudinal Characteristics Of Equity Investors, Asian Journal Of Research In Social Sciences And Humanities, Vol. 6, No. 10, October 2016, Pp. 1427-1440.

[11] Mahalakshmi T.N. 1 \&Anuradha N. (2018), Factors affecting Investment Decision making \& Investment Performance among Individual Investors in India, International Journal of Pure and Applied Mathematics, Volume 118, No. 18, 2018, 1667-1675, ISSN: 1311-8080 (printed version); ISSN: 1314-3395 (on-line version), url: http://www.ijpam.eu

[12] Muhammad Zubair Tauni, Zia-Ur-Rehman Rao, Hongxing Fang, Sultan Sikandar Mirza, Zulfiqar Ali Memon, Khalil Jebran (2017), Do Investor's Big Five Personality Traits Influence The Association Between Information Acquisition And Stock Trading Behavior?, China Finance Review International , Vol. 7 No. 4, 2017 Pp. 450-477.

[13] Nasrullah Hamza, Imtiaz Arif (2019) Impact Of Financial Literacy On Investment Decisions: The Mediating Effect Of BigFive Personality Traits Model, Market Forces College Of Management Sciences, Volume 14, Issue 1 June 2019, Pp:43- 60 
[14] Olga Pak, Impact Of Personality On Risk Tolerance And Investment Decisions(2015), International Journal Of Commerce And Management, Volume:25, Issue(4), 2015, pp:370-384.

[15] P.Parameswari, Dr. Jayasree Krishnan (2015), Personality Traits And Risk Profile Influencing Attitude Of Investor, Indian Journal Of Research (Paripex), Volume : 4 | Issue : 5 | May 2015 Issn - 2250-1991.

[16] Penerbit Akademia Baru (2017), The Effects Of Behavioural Factors In Investment Decision Making At Pakistan Stock Exchanges,

https://www.Researchgate.Net/Publication/330673360

[17] Renu Isidore (2017), Review Of The Influence Of Investor Personality (The Big 5 Model)On Investor Behavior, https://www.Researchgate.Net/Publication/319328319

[18] Swarna Lata Verma (2018), Role Of Personality Traits In Making Investment Decisions: A Case Of Residential Energy

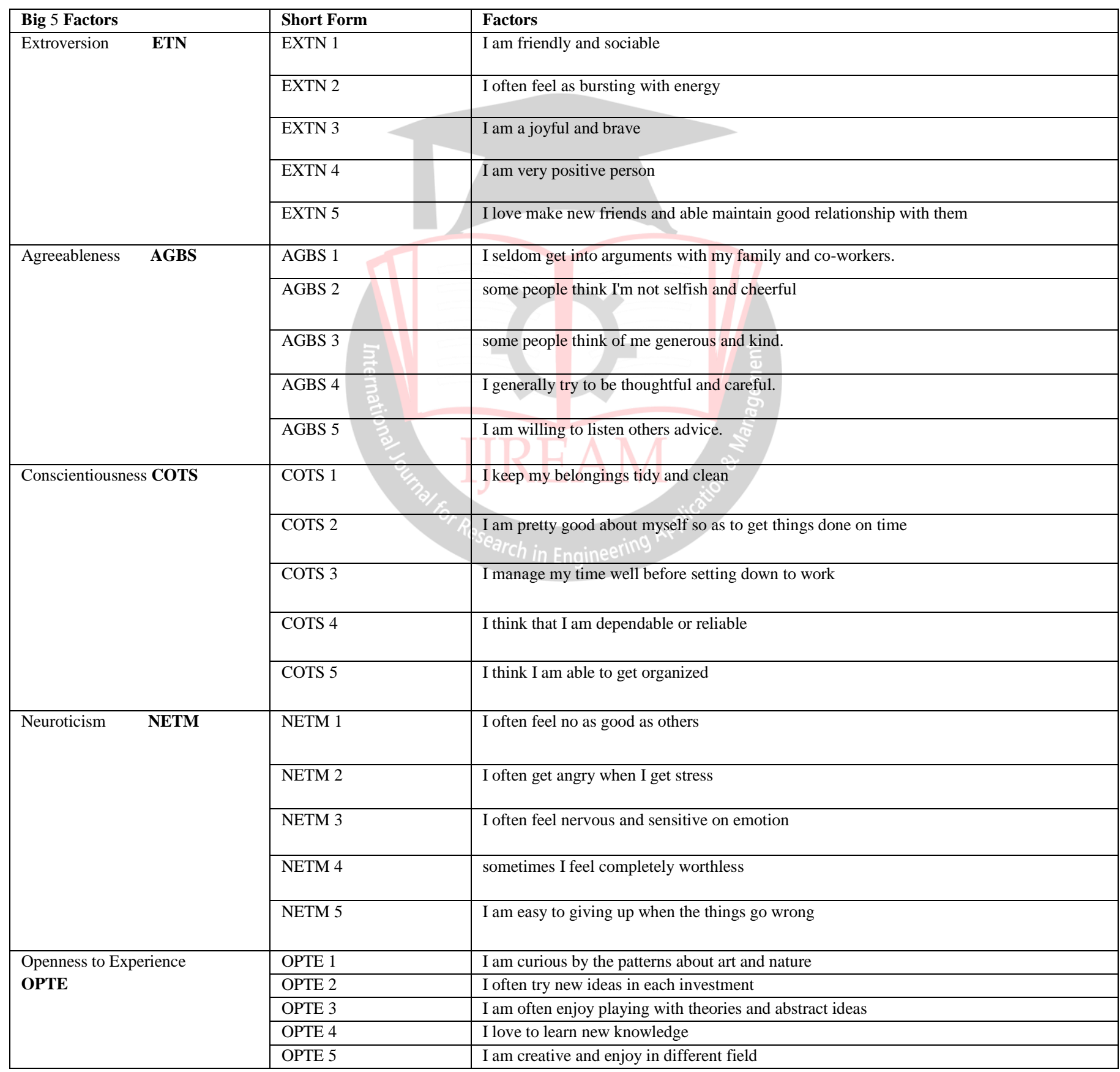

Efficiency, International Research Journal Of Social Sciences (Int. Res. J. Social Sci.), Vol. 7(6), 46-48, June (2018), ISSN 2319-3565, Pp: $46-48$ Joseph D (2004), The Big Five Personality Traits and Individual Job Performance Growth Trajectories in Maintenance and Transitional Job Stages, Journal of Applied Psychology, 2004, Vol 89, No. 5, pp 835 - 853.

[20] Zafar Uz Zaman Anjum, Nazar H.Phulpoto, Sohail A. Memon, Raza M. Pahore, M. Imran, Zuhaibuddin Bhutto (2019), Impact Of Psychological Biases And Personality Traits On Investor Trading Behaviour, IJCSNS International Journal Of Computer Science And Network Security, VOL.19 No.8, August 2019, Pp:115-122.
[19] Thoresen Carl J, Bradley Jill C, Bliese Paul D, Thoresen

\section{Annexure:}

